\title{
Genome-wide microsatellite characteristics of five human Plasmodium species, focusing on Plasmodium malariae and $P$. ovale curtisi
}

\author{
Vivek Bhakta Mathema $^{1}$, Supatchara Nakeesathit ${ }^{2}$, Nicholas J. White ${ }^{2,3}$, Arjen M. Dondorp ${ }^{2,3}$, and Mallika Imwong ${ }^{1, *}$ \\ ${ }^{1}$ Department of Molecular Tropical Medicine and Genetics, Faculty of Tropical Medicine, Mahidol University, 10400 Bangkok, Thailand \\ ${ }^{2}$ Mahidol-Oxford Tropical Medicine Research Unit, Faculty of Tropical Medicine, Mahidol University, 10400 Bangkok, Thailand \\ ${ }^{3}$ Centre for Tropical Medicine and Global Health, Nuffield Department of Medicine, University of Oxford, OX1 2JD Oxford, \\ United Kingdom
}

Received 9 September 2019, Accepted 30 April 2020, Published online 15 May 2020

\begin{abstract}
Microsatellites can be utilized to explore genotypes, population structure, and other genomic features of eukaryotes. Systematic characterization of microsatellites has not been a focus for several species of Plasmodium, including $P$. malariae and $P$. ovale, as the majority of malaria elimination programs are focused on $P$. falciparum and to a lesser extent $P$. vivax. Here, five human malaria species ( $P$. falciparum, $P$. vivax, $P$. malariae, $P$. ovale curtisi, and $P$. knowlesi) were investigated with the aim of conducting in-depth categorization of microsatellites for $P$. malariae and $P$. ovale curtisi. Investigation of reference genomes for microsatellites with unit motifs of $1-10$ base pairs indicates high diversity among the five Plasmodium species. Plasmodium malariae, with the largest genome size, displays the second highest microsatellite density (1421 No./Mbp; 5\% coverage) next to P. falciparum (3634 No./Mbp; $12 \%$ coverage). The lowest microsatellite density was observed in $P$. vivax (773 No./Mbp; $2 \%$ coverage). A, AT, and AAT are the most commonly repeated motifs in the Plasmodium species. For $P$. malariae and $P$. ovale curtisi, microsatellite-related sequences are observed in approximately 18-29\% of coding sequences (CDS). Lysine, asparagine, and glutamic acids are most frequently coded by microsatellite-related CDS. The majority of these CDS could be related to the gene ontology terms "cell parts," "binding," "developmental processes," and "metabolic processes." The present study provides a comprehensive overview of microsatellite distribution and can assist in the planning and development of potentially useful genetic tools for further investigation of $P$. malariae and $P$. ovale curtisi epidemiology.
\end{abstract}

Key words: Tandem repeats, Gene ontology, Microsatellite markers, Malaria.

Résumé - Caractéristiques à l'échelle du génome des microsatellites de cinq espèces humaines de Plasmodium, spécialement Plasmodium malariae et $\boldsymbol{P}$. ovale curtisi. Les microsatellites peuvent être utilisés pour explorer les génotypes, la structure de la population et d'autres caractéristiques génomiques des eucaryotes. La caractérisation systématique des microsatellites n'a pas été étudiée pour plusieurs espèces de Plasmodium, dont $P$. malariae et $P$. ovale, car la majorité des programmes d'élimination du paludisme se concentrent sur $P$. falciparum et, dans une moindre mesure, $P$. vivax. Dans cet article, cinq espèces causant le paludisme humain $(P$. falciparum, $P$. vivax, $P$. malariae, $P$. ovale curtisi et $P$. knowlesi) ont été étudiées dans le but de procéder à une catégorisation approfondie des microsatellites pour $P$. malariae et $P$. ovale curtisi. L'étude des génomes de référence pour les microsatellites avec des motifs unitaires de 1 à 10 paires de bases indique une grande diversité parmi les cinq espèces de Plasmodium. Plasmodium malariae, avec la plus grande taille de génome, affiche la deuxième densité de microsatellites la plus élevée (1421 No./Mpb ; $5 \%$ de couverture) après $P$. falciparum (3634 No./Mpb ; $12 \%$ de couverture). La plus faible densité de microsatellites a été observée chez $P$. vivax (773 No./Mpb ; $2 \%$ de couverture). A, AT et AAT sont les motifs les plus fréquemment répétés chez les espèces de Plasmodium. Pour $P$. malariae et $P$. ovale curtisi, des séquences liées aux microsatellites sont observées dans environ 18 à $29 \%$ des séquences codantes (CDS). La lysine, l'asparagine et les acides glutamiques sont les plus souvent codés par les CDS liés aux microsatellites. La majorité de ces CDS pourrait être liée aux termes d'ontologie génétique "parties cellulaires », « liaison », «processus de développement » et «processus métaboliques ». Cette étude fournit un aperçu complet de la distribution des microsatellites et peut aider à la planification et au développement d'outils génétiques potentiellement utiles pour une étude plus approfondie de l'épidémiologie de $P$. malariae et $P$. ovale curtisi.

*Corresponding author: mallika.imw@mahidol.ac. th

This is an Open Access article distributed under the terms of the Creative Commons Attribution License (https://creativecommons.org/licenses/by/4.0), which permits unrestricted use, distribution, and reproduction in any medium, provided the original work is properly cited. 


\section{Introduction}

Recent advancements in gene sequencing technologies and the increasing availability of online genomic resources have made it possible to computationally explore genomic features of an organism that were previously inaccessible [18]. Molecular genetics and polymorphism studies involving microsatellites are among the key beneficiaries of such technological advancement. Microsatellites are short tandem repeats of DNA usually consisting of 1-10 base pair (bp) unit nucleotide motifs. Such microsatellites are known to be formed due to mispairing, improper alignment, and strand-slippage events [13, 22, 25]. Microsatellites with unit motifs of $2-3$ bp are often designated as short tandem repeats, simple sequence repeats, and simple sequence length polymorphisms [44, 64]. Moreover, these microsatellites can be characterized as (i) perfect repeats containing only pure motifs with $100 \%$ identical copies and constituting only one motif type; (ii) imperfect repeats containing motifs with mutations such as insertions, deletions, or substitution; and (iii) compound microsatellites containing stretches of two or more different repeat motifs [8]. These short tandem repeats of DNA can be highly polymorphic and are widely distributed throughout the genome of eukaryotic cells. Microsatellites are usually abundant in non-coding regions of the genome and can be targeted to produce polymerase chain reaction (PCR) products as markers to identify genetic diversity among a population [13, 25]. Currently, microsatellite markers are implemented across wide fields of biology, including gene linkage, genotyping, forensics, kinship relationships, phylogenetic analysis, and others [54]. Conventional procedures for microsatellite studies consist of in vitro microsatellite motif cloning, which is screening of cloned libraries for restricted motif types with often limited prior knowledge of microsatellite categorization and distribution. Such protocols are expensive, time-consuming, suffer from low modularity, and are prone to experimental errors. In contrast, recent years have witnessed a stark increase in the use of in silico tools for the analysis of microsatellites utilizing publicly available genomic databases [55]. Moreover, entire online platforms dedicated to particular groups of organisms (e.g., PlasmoDb and VivaxGen) and genome projects are significantly enhancing the range and accuracy of in silico analysis approaches [4, 62].

Decades long malaria intervention strategies have significantly reduced the number of malaria cases and fatalities worldwide. The Greater Mekong Subregion (GMS) has achieved significant progress in reducing the disease burden to meet their target of malaria elimination by 2015-2030. The GMS countries have achieved a $54 \%$ reduction in the incidence of malaria cases between 2012 and 2015 and the death rate has fallen by $84 \%$ over the same period [66]. The actual drug efficacy and burden of non-falciparum malaria still remain unclear due to the lack of sufficient epidemiological tools to investigate these parasite variants.

Instead of targeting all Plasmodium species, most malaria elimination programs are predominantly directed toward $P$. falciparum and to a lesser extent $P$. vivax [33]. Non$P$. falciparum malaria, mainly by $P$. malariae and $P$. ovale, still presents a major challenge for malaria eradication [32, 68]. Plasmodium malariae infects humans and causes fever. These infections are usually asymptomatic with low parasitemia but may cause chronic anemia and nephrotic syndrome [12, 17, 29, 41]. Plasmodium ovale can be subcategorized into two distinct species, $P$. ovale curtisi and $P$. ovale wallikeri, which only differ by small genetic variations and a shorter latency period in $P$. ovale wallikeri [39]. These sympatric-occurring $P$. ovale subspecies are generally indistinguishable morphologically. Infections by either of these $P$. ovale subspecies present with mild fever and are currently treated with the conventional antimalarial drug chloroquine [40]. Plasmodium ovale can undergo the hypnozoite stage, which is a dormant stage in the liver. This enables concealment from diagnosis, and reactivation may occur weeks, months, or even years after the initial infection, leading to disease relapse [21, 48]. This parasite is endemic throughout parts of Asia, Africa, South America, and the Western Pacific [29, 43, 50, 69].

Recent epidemiological studies conducted in Cameroon [47] and Equatorial Guinea [53] have revealed the presence of over $12 \%$ P. malariae followed by $1-6 \%$ P. ovale-positive samples in parts of Uganda and Bioko [43]. Separate studies conducted in Tanzania indicate persistent transmission of $P$. malariae and $P$. ovale in an area of declining $P$. falciparum [68]. These findings collectively signal the significant presence of these parasites and reveal an epidemiologic knowledge gap between them and other well-studied Plasmodium species [51].

Barely adequate genetic markers available for $P$. malariae and $P$. ovale curtisi compared to $P$. falciparum $[2,16,20$, 57] and $P$. vivax $[19,24,37]$ self-elaborate the low emphasis being given to these parasites. Microsatellite-based schemes would greatly facilitate population genetics and therapeutic studies in $P$. malariae and $P$. ovale curtisi. Large genome size $(\sim 29 \mathrm{Mbp})$ with high AT content $(\sim 75 \%)$ ideally make microsatellite-based genotyping markers a suitable means for investigating epidemiology and population genetics of these Plasmodium species [4]. This study aims to present comprehensive categorization of the microsatellite distribution of major human malaria-causing Plasmodium species with a focus on $P$. malariae and $P$. ovale curtisi, which may also contribute to the development of additional genotyping markers for this parasite.

\section{Materials and methods \\ Sequencing data}

This study is a review and bioinformatics analysis of microsatellites in five human malaria-causing Plasmodium species based on whole genome sequencing data available in the PlasmoDB database. The whole genome sequences of $P$. malariae $\mathrm{UG} 01, P$. falciparum 3D7, $P$. vivax SAL-1, $P$. ovale curtisi $\mathrm{GH} 01$, and $P$. knowlesi STRAIN-H were downloaded from the PlasmoDB webserver (http://plasmodb.org/ common/downloads/release-36/) [4]. Plasmodium ovale wallikeri was not included in the analysis due to its close genetic relatedness to $P$. ovale curtisi and lack of a standardized reference genome in the PlasmoDB database [4, 43]. Nucleotide sequences of all predicted and known coding sequence (CDS) regions for each Plasmodium species were obtained using the PlasmoDB webserver's built-in gene resource 
Table 1. Genome-wide coverage and density of microsatellites in the genomes of five Plasmodium species.

\begin{tabular}{|c|c|c|c|c|c|c|}
\hline Type & Microsatellite features & $\begin{array}{c}\text { P. falciparum } \\
\text { 3D7 }\end{array}$ & $\begin{array}{l}\text { P. vivax } \\
\text { SAL-1 }\end{array}$ & $\begin{array}{l}\text { P. malariae } \\
\text { UG01 }\end{array}$ & $\begin{array}{c}\text { P. ovale curtisi } \\
\text { GH01 }\end{array}$ & $\begin{array}{l}\text { P. knowlesi } \\
\text { STRAIN-H }\end{array}$ \\
\hline \multirow{9}{*}{$\begin{array}{l}\text { Genome-wide } \\
\text { microsatellites }\end{array}$} & Sequence analyzed (bp) & $23,332,839$ & $27,013,980$ & $33,618,035$ & $33,479,509$ & $24,395,979$ \\
\hline & Genomic GC content $(\%)$ & 19.34 & 42.19 & 24.38 & 28.48 & 38.60 \\
\hline & No. of microsatellites & 84,786 & 20,875 & 47,762 & 29,245 & 32,008 \\
\hline & Microsatellite density (No./Mbp) & 3633.76 & 772.75 & 1420.73 & 873.52 & 1312.02 \\
\hline & Microsatellite occurrence per $2 \mathrm{~Kb}$ & 7.30 & 1.55 & 2.84 & 1.75 & 2.62 \\
\hline & Total length of microsatellite (bp) & $2,698,077$ & 591,020 & $1,663,135$ & 793,213 & $1,129,172$ \\
\hline & Microsatellite coverage (bp/Mbp) & $115,634.32$ & $21,878.30$ & $49,471.51$ & $23,692.49$ & $46,285.17$ \\
\hline & Perfect microsatellites $(\%)$ & 56.09 & 70.22 & 61.71 & 76.70 & 71.32 \\
\hline & Genome content by microsatellite (\%) & 11.56 & 2.19 & 4.95 & 2.37 & 4.63 \\
\hline \multirow[t]{5}{*}{ CDS microsatellites } & No. of microsatellites & 9284 & 1766 & 4107 & 2364 & 1447 \\
\hline & Microsatellite density (No./Mbp) & 397.89 & 65.37 & 122.17 & 70.61 & 59.31 \\
\hline & Total length of microsatellites (bp) & 367,916 & 59,733 & 184,537 & 83,447 & 43,055 \\
\hline & Microsatellite coverage (bp/Mbp) & $15,768.16$ & 2211.19 & 5489.23 & 2492.48 & 1764.84 \\
\hline & Perfect microsatellites $(\%)$ & 47.73 & 50.23 & 48.31 & 56.98 & 59.23 \\
\hline
\end{tabular}

download tools. The Plasmodium strains with maximum known genes and transcripts in the PlasmoDB webserver were selected for each species under evaluation. The total number of nucleotide base pairs scanned for microsatellites and whole genome GC\% content of each organism are listed in Table 1. For P. malariae and P. ovale curtisi, sets of 6573 and 7162 sequences representing $\geq 98 \%$ of the total available CDS (known and predicted proteins) from the whole-genome sequence were included for evaluation.

\section{Microsatellite analysis}

Identification and categorization of perfect and imperfect microsatellites was performed with the highly accurate tandem repeat search tool Phobos version 3.3.11 (http://www.ruhr-unibochum.de/ecoevo/cm/cm_phobos.htm) $[35,56]$. The total GC\% content and basic genomic statistics for each parasite sample were calculated with the python script multifastats.py (https:// github.com/davidrequena/multifastats/blob/master/multifastats. py). The detection criteria for tandem repeats was restricted to evaluation of perfect and imperfect repeats with unit motifs of 1-10 bp with a minimum threshold repeat number of $14,7,5$, 4, 4, 4, 4, 4, 4, and 4 for mono-, di-, tri-, tetra-, penta-, hexa-, hepta-, octa-, nona-, and deca-nucleotide microsatellites, respectively. For protein sequences, microsatellite GC content and tandemly repeated residues with a minimum of four repeats and maximum unit motif length of three amino acids were considered for evaluation using OSTRFPD [34]. Analysis of tandemly repeated amino acid sequences for $P$. malariae and $P$. ovale curtisi included the entire set of CDS available in the PlasmoDB online database.

\section{Heatmaps and genomic visualization of microsatellites}

Clusters of microsatellites present in CDS regions of each chromosome were visualized as heatmaps using the seaborn library-backend python script (https://seaborn.pydata.org) with Euclidean metrics and complete linkage as measurement parameters. Scatter plots with Spearman's correlation coefficients were generated to compute correlations between unit motif length and frequency of microsatellites using the seaborn library-backend python script. Statistical significance was defined as $p$-values $<0.05$. Circos version 0.67-7 (http:// circos.ca/) was used to visualize the genome-wide distribution of microsatellites.

\section{Gene ontology analysis}

The Gene ontology (GO) terms associated with the cellular components, molecular functions, and biological processes for the microsatellite-associated protein sequences were computed by the deep neural-net-based hierarchical biological sequence classifier "SECLAF" using its default parameters trained on the UniProtKB GO database [58]. Microsatellite-associated proteins with the highest values of predicted GO terms each exceeding the 0.95 threshold score were included for analysis.

\section{Results}

\section{Abundance, distribution, and diversity of microsatellites in five Plasmodium species}

The analysis was conducted for both perfect and imperfect microsatellites with repeat numbers of $14,7,5,4,4,4,4,4,4$, and 4 for $1-10 \mathrm{bp}$ unit motif lengths, respectively, to minimize selection of nominal functional repeats related to the extreme AT-richness of some Plasmodium genomes. The genome-wide numbers of microsatellites identified among the five Plasmodium species were highly variable (84,786-20,875), along with the genomic coverage ranging from $11.56 \%$ to $2.19 \%$ (Table 1). The largest difference in both microsatellite density and coverage was observed between $P$. falciparum and $P$. vivax with densities of 3269.46 and 627.05 microsatellites per million base pairs (No./Mbp) and coverage of 115,634.32 and 21,878.30 microsatellite repeats per million base pairs (bp/Mbp), respectively. Plasmodium vivax exhibited the lowest microsatellite density (772.75 No./Mbp) and coverage $(21,878.30 \mathrm{bp} / \mathrm{Mbp})$. The average number of microsatellite occurrences for $P$. falciparum, $P$. vivax, $P$. malariae, and 
P. ovale were $7.3,1.55,2.84$, and 1.75 microsatellites per 2 kilobase pair $(\mathrm{kbp})$ genome length, respectively. Plasmodium malariae with the largest genome size harbored 47,762 microsatellites with a microsatellite density of 1420.73 No./Mbp, the second highest among all species investigated (Table 1). The highest and lowest percentages of perfect microsatellites were observed in $P$. ovale curtisi $(76.70 \%)$ and $P$. falciparum $(56.09 \%)$, respectively (Table 1$)$. The maximum $(76.70 \%)$ and minimum $(56.09 \%)$ percentages of perfect microsatellites were observed in $P$. ovale curtisi and $P$. falciparum, respectively (Table 1). The highest density (397.90 No./Mbp) and coverage $(15,768.16 \mathrm{bp} / \mathrm{Mbp})$ of CDS-associated microsatellites were observed in $P$. falciparum; the lowest density (65.37 No./Mbp) and coverage $(2211.19 \mathrm{bp} / \mathrm{Mbp})$ were observed in $P$. vivax (Table 1). Microsatellite density in $P$. malariae was 1.63 -fold higher than that in $P$. ovale curtisi (Table 1).

There was a high degree of diversity among the Plasmodium species in unit motif lengths of microsatellites across the respective genomes (Table 2). Plasmodium falciparum had the highest numbers and densities of mono- to penta-nucleotide long motif repeats, whereas $P$. vivax showed the lowest (Table 2). Plasmodium malariae showed the highest number of repeats for hexa-, octa-, and deca-nucleotide long motif repeats totaling 1648,1353 , and 1221, respectively. However, because of its large genome size, this did not translate to the highest repeat density or coverage of these motifs (Table 2). In general, the mono-, di-, and tri-nucleotide motifs were most abundant and collectively they accounted for approximately $80.0-90.0 \%$ of the total genome-wide unit motif length in all Plasmodium species. The highest proportions of mono-, di-, tri-, and tetranucleotides were observed in $P$. vivax $(74.46 \%), P$. falciparum (41.78\%), P. falciparum (8.19\%), and P. falciparum $(7.34 \%)$, respectively (Table 2). Plasmodium malariae was found to harbor the highest percentage of hexa-nucleotide long motifs $(3.45 \%)$ with a corresponding microsatellite density of 49.02 No./Mbp (Table 2). Interestingly, $P$. malariae had 3-fold higher microsatellite density compared to that of $P$. ovale curtisi for the unit motif lengths two, four, seven, and nine (Table 2). Nonetheless, $P$. falciparum, $P$. malariae, and $P$. ovale showed a clear negative correlation between $1 \mathrm{bp}$ and $10 \mathrm{bp}$ unit motif lengths and the frequency of microsatellite occurrence (Spearman's $R \leq-0.85, p \leq 1.6 \mathrm{e}-03)$. The negative correlation was also present for $P$. vivax (Spearman's $R=-0.33, p=0.35$ ) and $P$. knowlesi (Spearman's $R=-0.67, p=0.033$ ), albeit to a weaker degree (Fig. 1).

\section{A, AT, and AAT as the most dominant microsatellite motifs in Plasmodium genomes}

The microsatellite motif sequences show high diversity among the different Plasmodium species (Supplementary Table 1), although motif type A was repeated most frequently in all species of Plasmodium except $P$. falciparum, where AT $(41.62 \%)$ was the most common repeat. In contrast, AG was the least frequently occurring di-nucleotide motif in all Plasmodium species under investigation (Supplementary Table 1). The motifs A, AT, and AAT collectively accounted for more than $70 \%$ of all repeats in the studied species. Motifs containing only $\mathrm{C}$ and $\mathrm{G}$ were relatively rare $(<10 \%)$ for mono- and di-nucleotide repeats. Only $P$. vivax harbored frequently repeated tri-nucleotide motifs AGG with a microsatellite GC content $>50 \%$. In P. malariae, the number of mononucleotide motif repeats $\mathrm{A}$ was more than twice the number of di-nucleotide AT motif repeats (Supplementary Table 2).

The CDS microsatellite density distribution in proteincoding regions of Plasmodium analyzed for individual chromosomes was computed as heatmaps (Fig. 2). The highest microsatellite density was on chromosome 6 of P. falciparum (464.30 No./Mbp), and the lowest density was on chromosome 11 of $P$. knowlesi (43.70 No./Mbp). Heatmap analysis showed that $P$. falciparum (397.12 No./Mbp), $P$. malariae (137.67 No./Mbp), and $P$. ovale (109.50 No./Mbp) had an average CDS-associated chromosomal microsatellite density greater than 100 No./Mbp, whereas $P$. vivax (78.58 No./Mbp) and $P$. knowlesi (61.95 No./Mbp) showed average microsatellite densities of less than 100 No./Mbp (Fig. 2).

\section{Diversity of tandemly repeated amino acids in microsatellite-associated gene products of $\boldsymbol{P}$. malariae and $\boldsymbol{P}$. ovale curtisi and their ontology annotations}

Motif-wise distributions of microsatellites in the $P$. malariae and $P$. ovale curtisi chromosomes were investigated further. The mono-, di-, and tri-nucleotide motifs accounted on average for 50, 25, and $5 \%$ in P. malariae and 75,9 , and $2 \%$ in P. ovale curtisi of total unit motif repeats, respectively (Supplementary Table 2 ). The collective contribution of tri- to deca-nucleotide motifs was $\leq 10 \%$ of the total repeats in both species (Supplementary Table 2). On average, the chromosomal microsatellite densities for $P$. malariae and $P$ ovale curtisi were $1568.22 \pm 140.48$ and $1203.04 \pm 82.28$ No./Mbp, respectively. For $P$. malariae, the A, AT, and AAT unit repeat motifs were the most frequent, constituting 58, 28, and $3 \%$ of total chromosomal DNA microsatellites, respectively (Fig. 3a). The total microsatellite densities in non-coding regions were 7.87-10.01-fold higher than in the CDS regions (Fig. 3b). Aggregate GC content of CDS-associated microsatellites was approximately 2-fold higher (21.0\%) compared to that in the chromosomal region (Fig. 3c). Evaluation of the amino acid repeats in the annotated and predicted proteins available for $P$. malariae showed that lysine $(34.12 \%)$ and asparagine (29.58\%) were the most common amino acid repeats, corresponding to the most commonly observed tri-nucleotide repeats AAA (61\%) and AAT (4\%) (Fig. 3a and d). For P. ovale curtisi, the A, AT, and AAAAT repeat motifs were most frequent in aggregate chromosomal DNA, constituting $84 \%$, $9 \%$, and $2 \%$, respectively (Fig. $4 \mathrm{a}$ ). The microsatellite densities in non-coding regions were 7.77-12.20-fold higher than in CDS regions (Fig. 4b). Aggregate GC content of CDS-associated microsatellites was approximately 3-fold higher (30.0\%) compared to that of the chromosomal region (Fig. 4c). Evaluation of the amino acid repeats indicated that lysine $(34.12 \%)$ and asparagine $(29.58 \%$ ) were the most common amino acid repeats, corresponding to the most commonly observed tri-nucleotide repeats AAA (61\%) and AAT (4\%) (Fig. 4d).

For investigating functional annotation of the microsatelliteassociated CDS distribution, the SECLAF classifier was trained 
Table 2. Relative density and categorization of 1-10 bp unit motif length microsatellites in the genomes of five Plasmodium species.

\begin{tabular}{|c|c|c|c|c|c|c|}
\hline Unit motif length (bp) & Features & $\begin{array}{c}\text { P. falciparum } \\
\text { 3D7 }\end{array}$ & $\begin{array}{l}\text { P. vivax } \\
\text { SAL-1 }\end{array}$ & $\begin{array}{l}\text { P. malariae } \\
\text { UG01 }\end{array}$ & $\begin{array}{c}\text { P. ovale curtisi } \\
\text { GH01 }\end{array}$ & $\begin{array}{l}\text { P. knowlesi } \\
\text { STRAIN-H }\end{array}$ \\
\hline \multirow[t]{5}{*}{ Mononucleotide $(n=1)$} & No. & 27,687 & 15,544 & 24,320 & 20,985 & 23,807 \\
\hline & Percentage $(\%)^{\mathrm{a}}$ & 32.66 & 74.46 & 50.919 & 71.756 & 74.378 \\
\hline & No./Mbp & 1186.61 & 575.40 & 723.42 & 626.80 & 975.86 \\
\hline & Length coverage & 644,936 & 317,981 & 506,974 & 485,595 & 567,513 \\
\hline & Coverage/Mbp & $27,640.70$ & $11,770.98$ & $15,080.42$ & $14,504.24$ & $23,262.56$ \\
\hline \multirow[t]{5}{*}{ Dinucleotide $(n=2)$} & No. & 35,423 & 846 & 11,857 & 3721 & 2642 \\
\hline & Percentage $(\%)^{\mathrm{a}}$ & 41.779 & 4.053 & 24.86 & 12.724 & 8.254 \\
\hline & No./Mbp & 1518.16 & 31.38 & 352.69 & 111.14 & 108.30 \\
\hline & Length coverage & $1,155,503$ & 22,208 & 350,048 & 86,288 & 85,158 \\
\hline & Coverage/Mbp & $49,522.61$ & 822.09 & $10,412.51$ & 2577.34 & 3490.66 \\
\hline \multirow[t]{5}{*}{ Trinucleotide $(n=3)$} & No. & 6944 & 595 & 1911 & 840 & 772 \\
\hline & Percentage $(\%)^{\mathrm{a}}$ & 8.19 & 2.85 & 4.001 & 2.872 & 2.412 \\
\hline & No./Mbp & 297.61 & 22.03 & 56.84 & 25.09 & 31.64 \\
\hline & Length coverage & 243,265 & 15,766 & 84,872 & 25,951 & 21,436 \\
\hline & Coverage/Mbp & $10,425.87$ & 583.62 & 2524.60 & 775.13 & 878.67 \\
\hline \multirow[t]{5}{*}{ Tetranucleotide $(n=4)$} & No. & 6228 & 575 & 2247 & 686 & 646 \\
\hline & Percentage $(\%)^{\mathrm{a}}$ & 7.346 & 2.754 & 4.705 & 2.346 & 2.018 \\
\hline & No./Mbp & 266.90 & 21.28 & 66.90 & 20.49 & 26.48 \\
\hline & Length coverage & 172,622 & 18,218 & 120,340 & 26,431 & 23,432 \\
\hline & Coverage/Mbp & 7398.24 & 674.39 & 3579.63 & 789.47 & 960.49 \\
\hline \multirow[t]{5}{*}{ Pentanucleotide $(n=5)$} & No. & 2838 & 486 & 1510 & 841 & 809 \\
\hline & Percentage $(\%)^{\mathrm{a}}$ & 3.347 & 2.328 & 3.162 & 2.88 & 2.527 \\
\hline & No./Mbp & 121.63 & 17.99 & 44.92 & 25.12 & 33.16 \\
\hline & Length coverage & 98,990 & 16,494 & 65,863 & 27,158 & 34,798 \\
\hline & Coverage/Mbp & 4242.52 & 610.57 & 1959.16 & 811.18 & 1426.38 \\
\hline \multirow[t]{5}{*}{ Hexanucleotide $(n=6)$} & No. & 1635 & 523 & 1648 & 803 & 830 \\
\hline & Percentage $(\%)^{\mathrm{a}}$ & 1.928 & 2.505 & 3.45 & 2.746 & 2.593 \\
\hline & No./Mbp & 70.07 & 19.36 & 49.02 & 23.98 & 34.02 \\
\hline & Length coverage & 77,483 & 22,263 & 111,744 & 39,628 & 43,860 \\
\hline & Coverage/Mbp & 3320.77 & 824.13 & 3323.93 & 1183.65 & 1797.84 \\
\hline \multirow[t]{5}{*}{ Heptanucloetide $(n=7)$} & No. & 955 & 289 & 629 & 225 & 742 \\
\hline & Percentage $(\%)^{\mathrm{a}}$ & 1.126 & 1.384 & 1.317 & .769 & 2.318 \\
\hline & No./Mbp & 40.93 & 10.70 & 18.71 & 6.72 & 30.41 \\
\hline & Length coverage & 78,852 & 50,031 & 53,547 & 15,988 & 217,069 \\
\hline & Coverage/Mbp & 3379.44 & 1852.04 & 1592.81 & 477.56 & 8897.74 \\
\hline \multirow[t]{5}{*}{ Octanucleotide $(n=8)$} & No. & 1123 & 681 & 1353 & 383 & 872 \\
\hline & Percentage $(\%)^{\mathrm{a}}$ & 1.325 & 3.262 & 2.833 & 1.31 & 2.724 \\
\hline & No./Mbp & 48.13 & 25.21 & 40.25 & 11.44 & 35.74 \\
\hline & Length coverage & 65,740 & 39,529 & 124,078 & 25,271 & 68,224 \\
\hline & Coverage/Mbp & 2817.49 & 1463.28 & 3690.82 & 754.82 & 2796.52 \\
\hline \multirow[t]{5}{*}{ Nonanucleotide $(n=9)$} & No. & 1367 & 749 & 1066 & 465 & 474 \\
\hline & Percentage $(\%)^{\mathrm{a}}$ & 1.612 & 3.588 & 2.232 & 1.59 & 1.481 \\
\hline & No./Mbp & 58.59 & 27.73 & 31.71 & 13.89 & 19.43 \\
\hline & Length coverage & 102,348 & 46,073 & 108,343 & 37,044 & 36,635 \\
\hline & Coverage/Mbp & 4386.44 & 1705.52 & 3222.77 & 1106.47 & 1501.68 \\
\hline \multirow[t]{5}{*}{ Decanucleotide $(n=10)$} & No. & 586 & 587 & 1221 & 296 & 414 \\
\hline & Percentage $(\%)^{\mathrm{a}}$ & 0.691 & 2.812 & 2.556 & 1.012 & 1.293 \\
\hline & No./Mbp & 25.10 & 21.73 & 36.319 & 8.84 & 16.97 \\
\hline & Length coverage & 41,816 & 44,108 & 137,797 & 24,354 & 32,881 \\
\hline & Coverage/Mbp & 1792.15 & 1632.78 & 4098.90 & 727.43 & 1347.80 \\
\hline
\end{tabular}

${ }^{\text {a }}$ Number of microsatellites of unit motif length $(n) /$ total number of microsatellites.

for over $980 \mathrm{GO}$ classes with an area under the curve (AUC) of $99.45 \%$ [28], providing a rough estimate of GO for largely unclassified microsatellite-linked proteins of $P$. malariae and $P$. ovale curtisi. For $P$. malariae and $P$. ovale curtisi, only 2054 and 1555 sequences were assigned to specific gene names and descriptions, respectively. In total, 1919 and 1271 distinct
CDS were found to contain at least one microsatellite for $P$. malariae and P. ovale curtisi, respectively. For P. malariae, three major GO categories, cellular component, molecular function, and biological process, were assigned to 229, 810, and 874 microsatellite-associated proteins. Within the categories, the top three GO terms collectively represent at least $25 \%$ of the total 

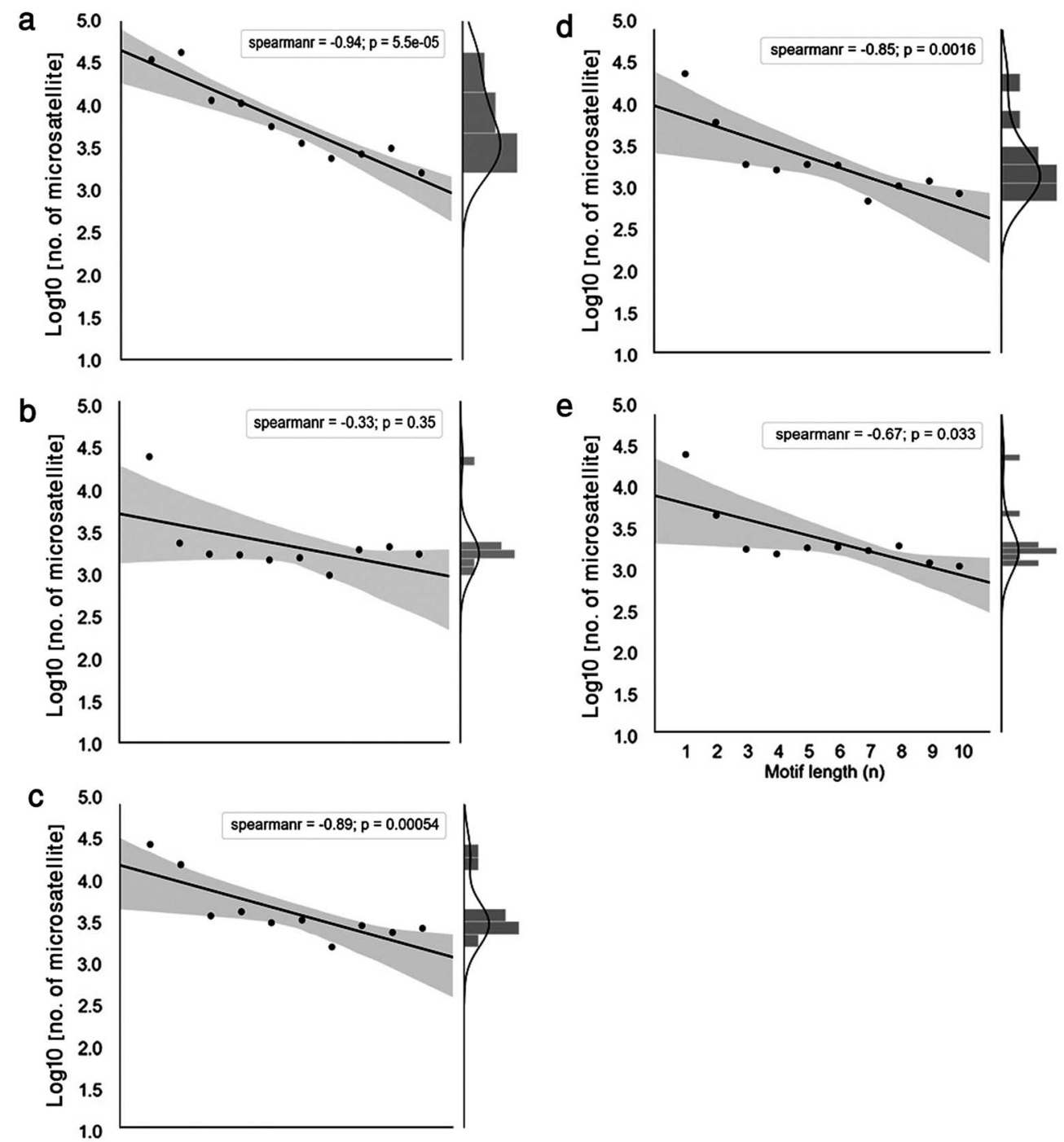

Figure 1. Unit motif length and frequency of microsatellites in seven Plasmodium species. Distribution of microsatellites in five species of Plasmodium expressed as percentage of motif length for (a) P. falciparum 3D7, (b) P. vivax SAL-1, (c) P. malariae UG01, (d) P. ovale curtisi GH01, and (e) P. knowlesi STRAIN-H. Trend line indicates logarithmic decline in number of microsatellites with increase in motif length. Histograms associated with each scatter plot represent kernel density estimates for frequency of unit motif type.

GO diversity. Regarding microsatellite-associated proteins under the "cellular component" GO category, the GO terms "cell parts," "protein-containing complex," and "intracellular part" collectively constituted over $40 \%$ of the total ontologies (Fig. 5a). The three major GO terms with regard to molecular function for microsatellite-associated proteins were "binding," "protein binding," and "translation regulatory activity" (Fig. 5b). The three major GO terms constituting "biological process" were "metabolic process," "reproduction," and "organic substance metabolic process" (Fig. 5c). For P. ovale curtisi, three major GO categories, cellular component, molecular function, and biological process, were assigned to 513, 146, and 446 microsatellite-associated proteins, respectively. In each category, the top three GO terms collectively represented at least $30 \%$ of the total GO diversity. GO categorized under "cellular component" displayed "cell parts," "intracellular part," and "cytoplasmic part" as the three major GO terms that collectively constituted over $40 \%$ of the total ontologies (Fig. 5a).
The three major GO terms with regard to molecular function for microsatellite-associated proteins were "binding," "protein binding," and "cell adhesion mediator activity" (Fig. 5b). The three major GO terms constituting "biological process" were "response to stimulus," "developmental process," and "immune system process" (Fig. 5c).

\section{Microsatellite distribution map for $\boldsymbol{P}$. malariae and $\boldsymbol{P}$. ovale curtisi}

A graphical representation (Fig. 6) comprising the entire known chromosomal DNA of $P$. malariae and $P$. ovale curtisi shows a relatively homogeneous distribution of microsatellites on each chromosome. For $P$. malariae and $P$. ovale, the density of genomic microsatellites in non-CDS sequences is $\geq 10$-fold greater than in CDS regions (Figs. $3 b$ and 5). Most of the microsatellites with smaller unit motifs $(<4 \mathrm{bp})$ were homogenously distributed, whereas microsatellites with longer unit 


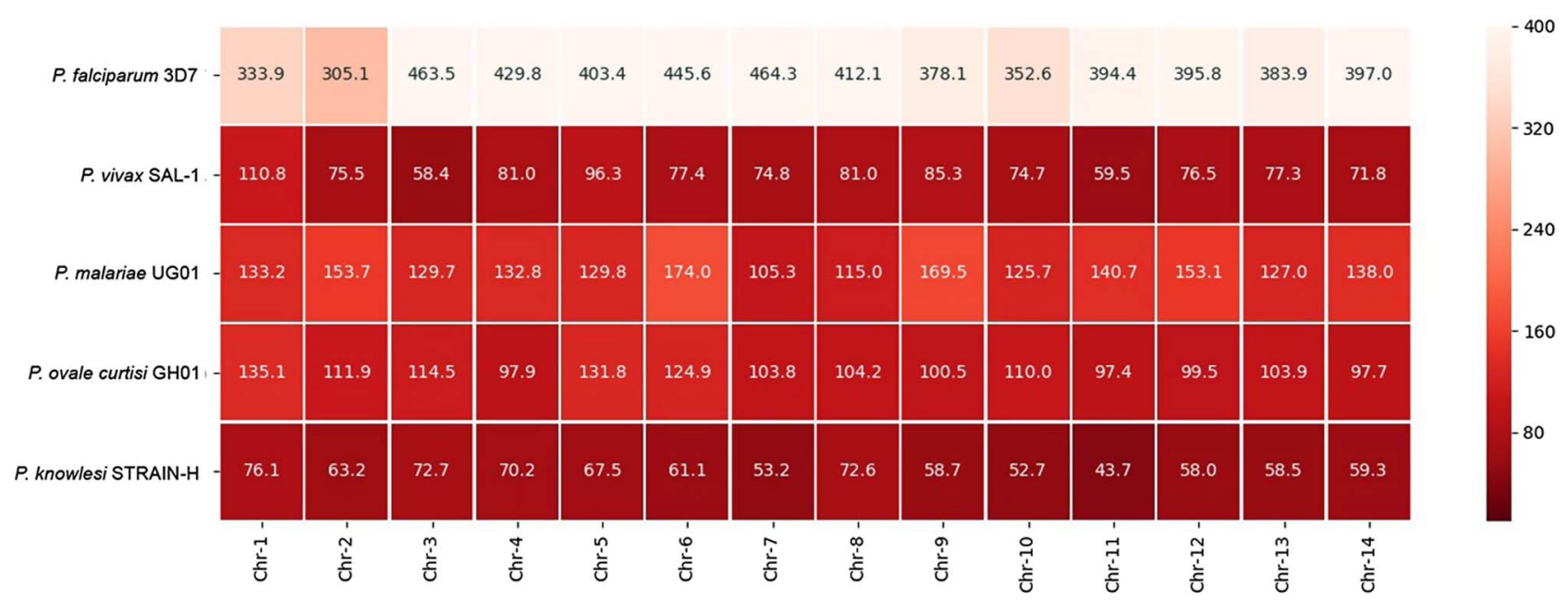

Figure 2. Microsatellite distribution in coding regions of seven Plasmodium species. Heatmap indicating microsatellites expressed as chromosomal density identified in coding regions (CDS) of five Plasmodium species. Heatmap color key indicates microsatellite density (No./Mbp). Chr, chromosome.

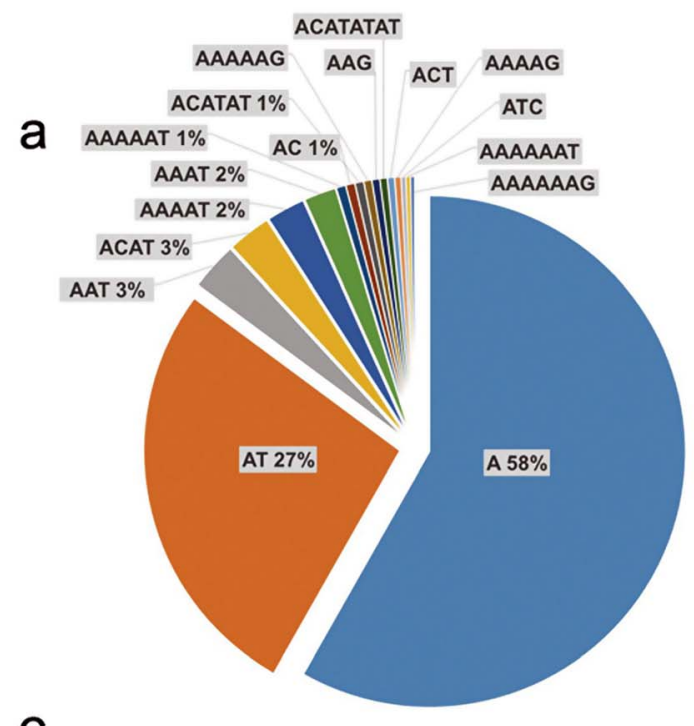

C

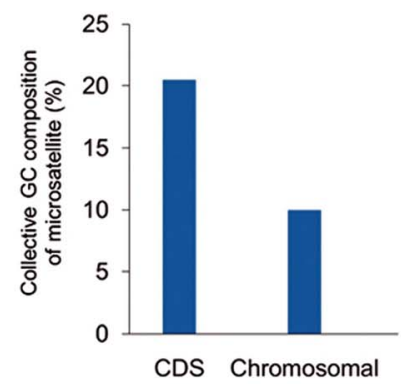

b
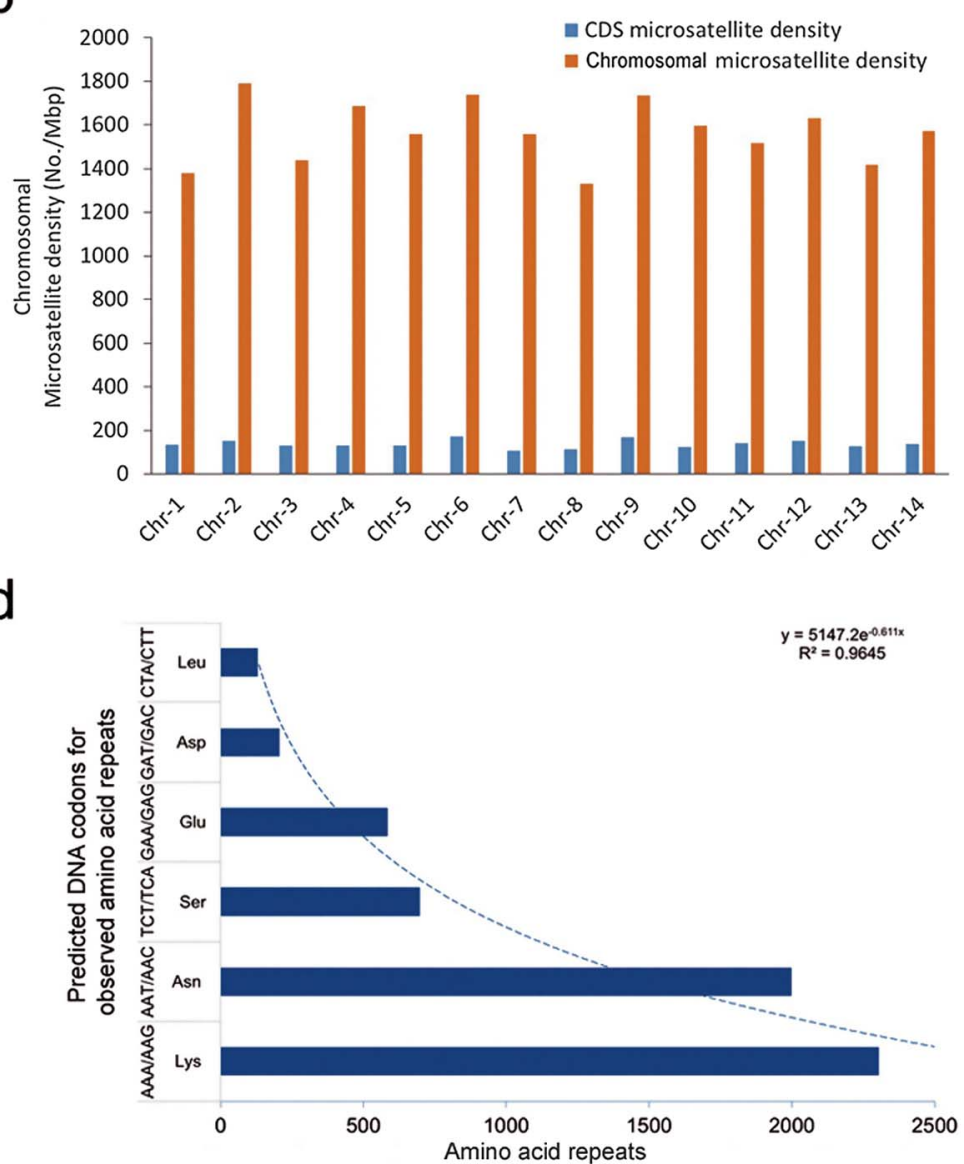

Figure 3. Microsatellite motif, chromosomal density, and tandemly repeated amino acid residue in Plasmodium malariae UG01. Representative charts for (a) 10 most frequently repeated motifs in chromosomes, (b) comparative distribution of total microsatellites in total chromosomal and coding sequences (CDS) expressed as microsatellite density, (c) aggregate GC content of microsatellites in CDS and total chromosomal sequences, and (d) six most frequent tandemly repeated amino acids associated with microsatellites. Trend line indicates logarithmic decline in number of tandemly repeated amino acids. 


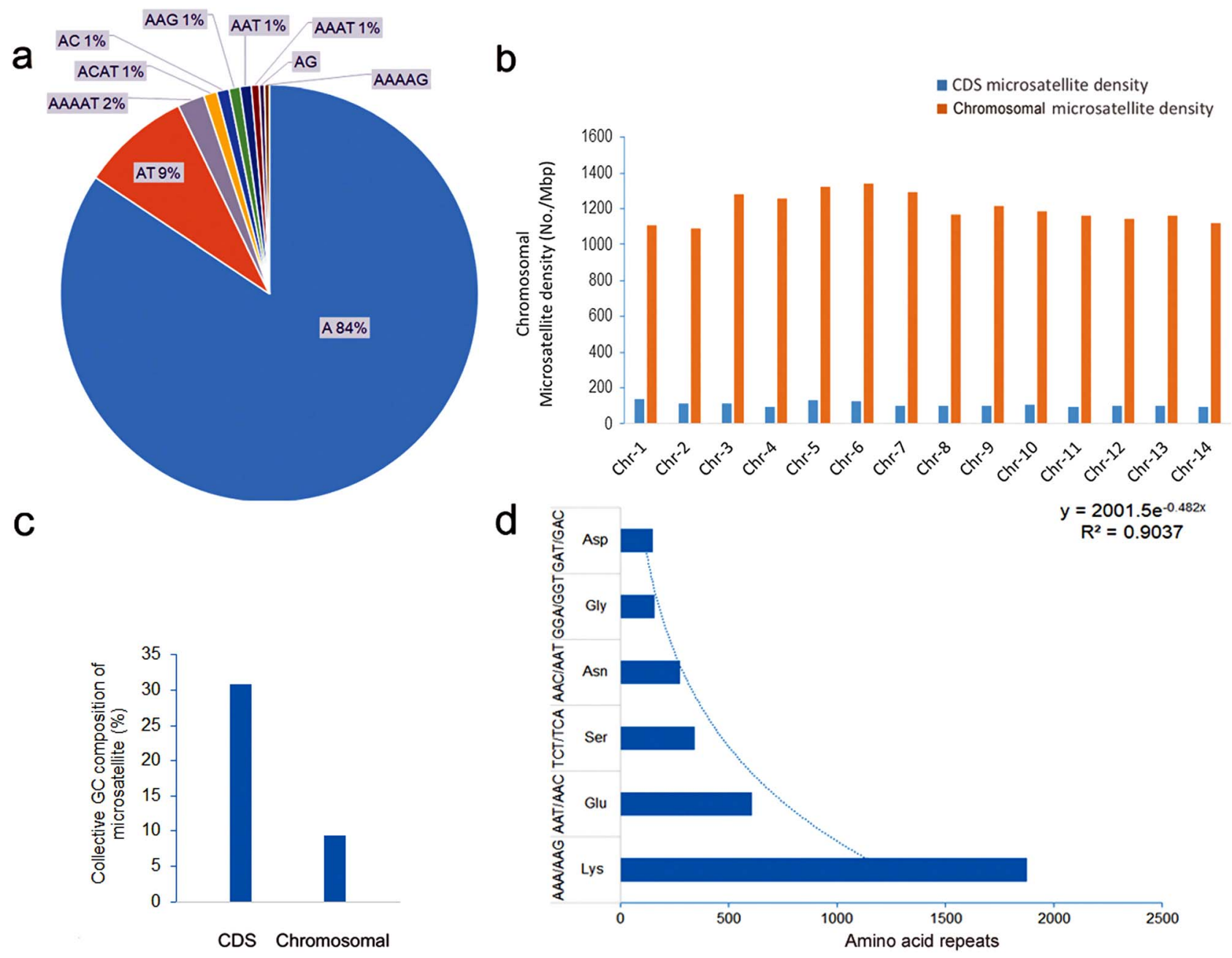

Figure 4. Microsatellite motif, chromosomal density and tandemly repeated amino acid residue in Plasmodium ovale curtisi GH01. Representative charts for (a)10 most frequently repeated motifs in chromosomes, (b) comparative distribution of total microsatellites in total chromosomal and coding sequences (CDS) expressed as microsatellite density, (c) aggregate GC content of microsatellites in CDS and total chromosomal sequences, and (d) six most frequent tandemly repeated amino acids associated with microsatellites. Trend line indicates logarithmic decline in number of tandemly repeated amino acids.

motifs ( $>4 \mathrm{bp}$ ) appeared to be more concentrated toward the middle region of the chromosome (Fig. 6, Supplementary Figures 1 and 2). In general, 1-3 unit motif microsatellites had high densities (Supplementary Figure 3). The genome-wide microsatellites with longer repeats, which appeared as peaks in the line chart within the map, were found to be more frequent around the middle region of most chromosomes (Fig. 6).

\section{Discussion}

In the absence of a standardized classification metric, the present study provides a comprehensive categorization and distribution of microsatellites in five human malaria-causing Plasmodium species. Strand slippage mutations, improper pairing, and host-parasite adaptation history may have contributed to the wide variation in microsatellite density and GC\% content among the Plasmodium species. At present, aside from the distinct individual genomic nature of each Plasmodium species and wide variation in GC\% content, there is no concrete evidence to justify or speculate on the observed variations in microsatellite motifs among the species. Previous studies have suggested microsatellites as a major contributor for genetic diversity in P. falciparum and $P$. vivax populations $[45,59$, 61]. Such high densities of short tandem repeats not only increase nucleotide polymorphisms but also complicate genetic analysis [5, 59, 61]. Earlier studies without the availability of the highly accurate Phobos search tool have suggested that a microsatellite may occur for every $2-3 \mathrm{kbp}$ in the $P$. falciparum genome [1]. The present survey of the $P$. falciparum genome shows comparatively high microsatellite density, totaling 3633.76 No./Mbp, which corresponds to approximately six microsatellites per $2 \mathrm{kbp}$ genome length. The use of more sophisticated tools to evaluate perfect/imperfect microsatellites and the high quality of genome sequence might have contributed to the observed difference in current estimates. Microsatellites have been reported in over $9 \%$ of ORFs for the extremely AT-rich ( 80\%) P. falciparum genome, which is in agreement 
a

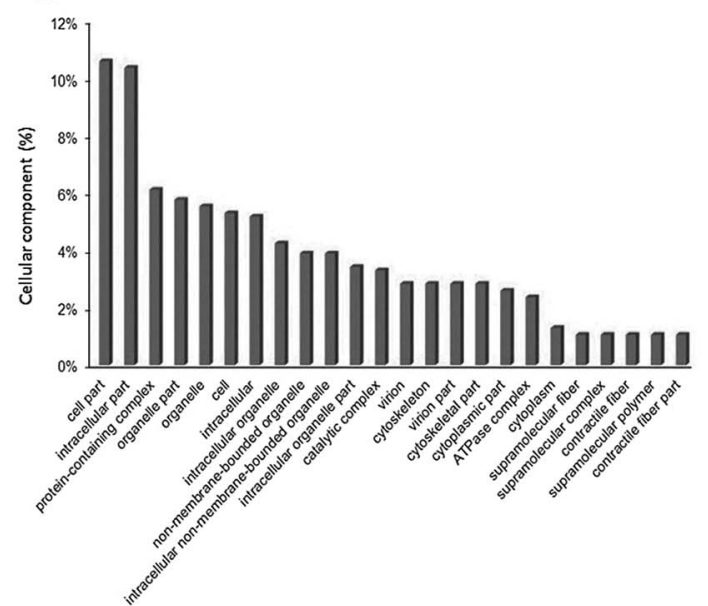

b

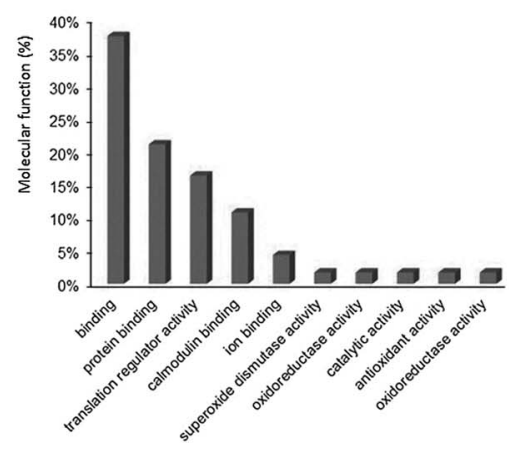

C
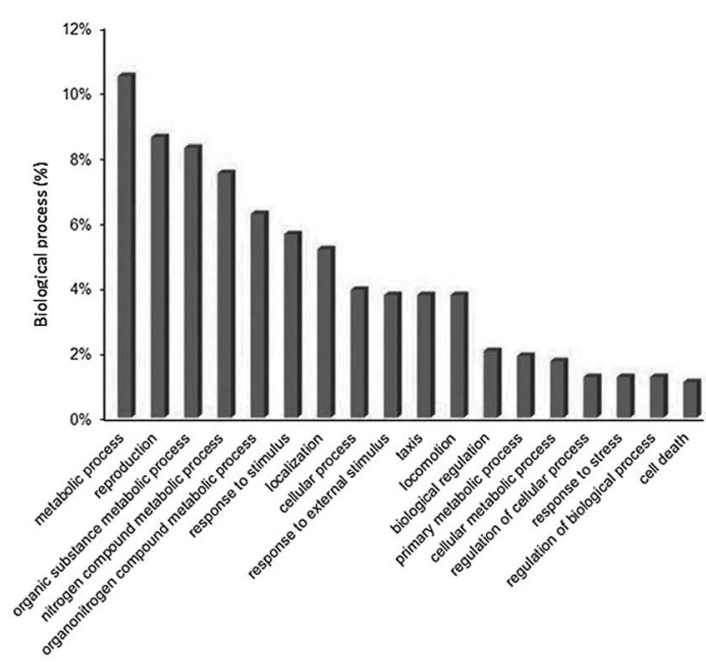
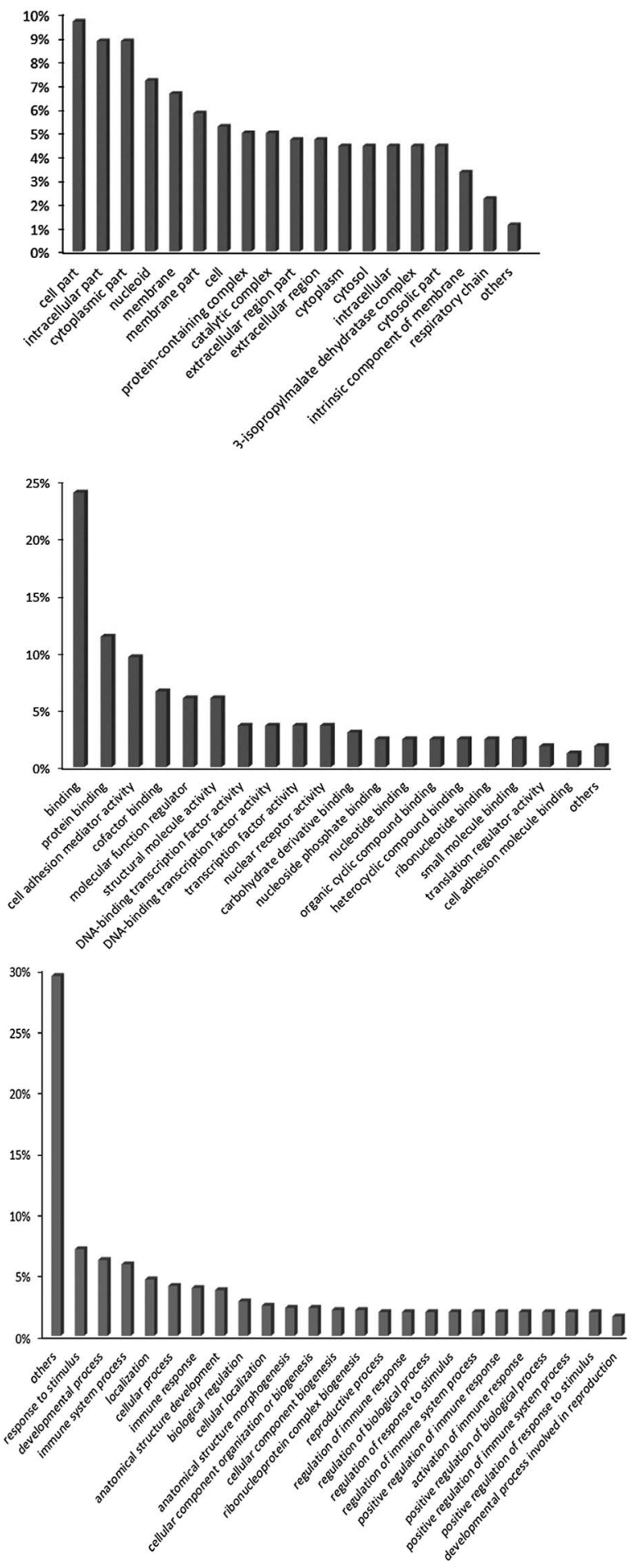

Figure 5. Gene ontology of microsatellites associated proteins in Plasmodium malariae UG01 (left) and P. ovale curtisi GH01 (right). Representative bar chart indicating the major gene ontologies of microsatellite-associated coding sequences (CDS) for (a) cellular component, (b) molecular function, and (c) biological process. Values for GO terms in the bar diagrams with less than 1.0-1.5\% coverage are not indicated.

with the current observation [59]. Likewise, a similar trend was visible for $P$. malariae and $P$. ovale curtisi, indicating substantial microsatellite-associated heterozygosity and its potential exploitation to access genomic diversity. All Plasmodium species displayed a logarithmic decline in the frequency of microsatellites with increasing unit motif length. This is likely 
a

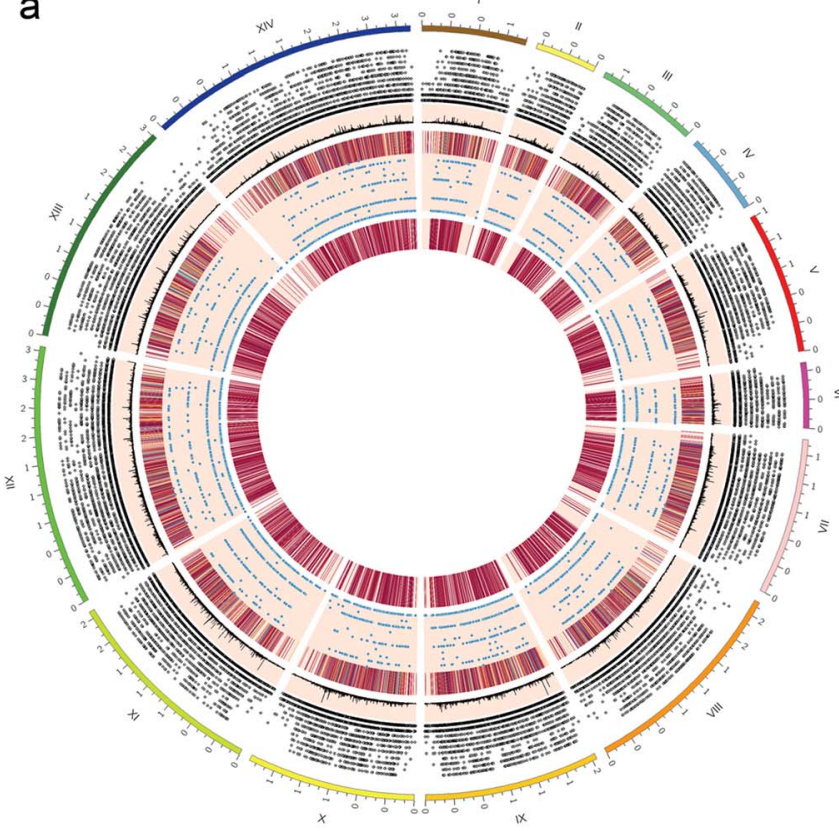

b

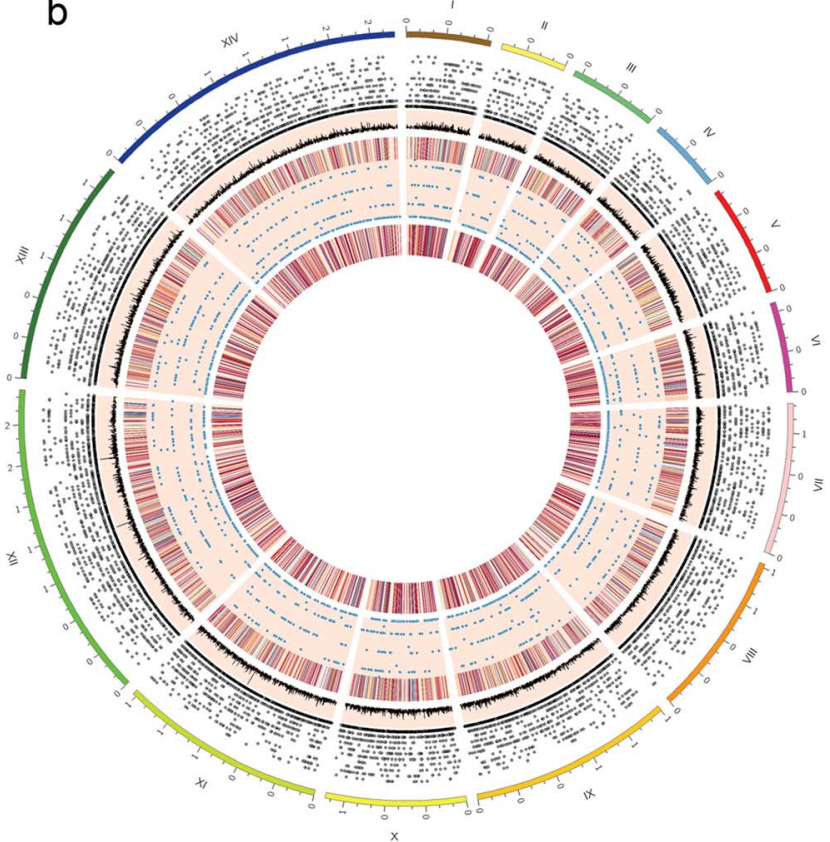

Figure 6. Genome-wide representation of microsatellite distribution map for Plasmodium malariae UG01 and P. ovale curtisi GH01. Different features indicated by microsatellite distribution map for (a) P. malariae UG01 and (b) P. ovale curtisi GH01 from outermost ${ }^{\mathrm{a}}$ to innermost ring can be interpreted as: chromosome 1-14 (I-XIV), scatter plotb ${ }^{\mathrm{b}}$ for genomic microsatellite distribution based on unit motif length which corresponds to the height of spot from base of its ring, line plot with peaks indicating regions with long repeat length, heatmap ${ }^{c}$ corresponding to the aggregate genomic microsatellite, scatter plot for microsatellites present in protein-coding region, heatmap for the aggregate microsatellites presenting in protein coding region of the genome. ${ }^{\mathrm{a}}$ Each unit difference in outermost ring represents chromosomal length of 1 mega base pair. ${ }^{\mathrm{b}, \mathrm{c}}$ Spots and regions in scatter plot and heatmap may appear overlapped due to high density but are physically apart in sequence.

to be related to the mechanisms of DNA slippage and DNA mismatch repair, which result in a greater likelihood of generating shorter AT-rich simple motifs [14, 28, 59]. The estimated slippage mutation rate within microsatellites has been suggested to increase exponentially as the length of the repeat motif increases [28]. This phenomenon is reflected by the observed high percentage of short perfect 1-3 unit motif microsatellites $(\geq 60 \%)$ in all species of Plasmodium under investigation. Thus, these factors result in a higher microsatellite mutation rate compared to the single point mutation rates. Escherichia coli [30], mice [10], humans [65], and P. falciparum [2] are reported to have microsatellite mutation rates of approximately $1 \times 10^{-2}$, $10^{-3}-10^{-4}, 1 \times 10^{-3}$, and $6.95 \times 10^{-5}-3.7 \times 10^{-4} / \mathrm{locus} /$ replication, respectively, which are all higher than the single point mutation rates in these organisms. A lack of analysis for Hardy-Weinberg equilibrium and linkage disequilibrium are among the few limitations of the present study as only the standard whole genome sequence of each Plasmodium species was investigated. Plasmodium malariae and P. ovale curtisi have over 1000 known microsatellite-related CDS constituting at least $10 \%$ of the entire genome, which are mainly distributed across 14 chromosomes [4]. Microsatellite instability in these CDS could promote protein domain duplication and production of homo-peptide tracts and interfere with transcript splicing, leading to disorders and disease [42, 67]. However, natural selection tends to favor suppression of tandem repeats in CDS compared to that in non-coding regions $[38,60]$. The extreme AT richness in P. falciparum has been reported to contribute to systematic mutational bias, resulting in abnormally high microstructural plasticity; thus, such studies have not yet been assessed for P. malariae [23]. Nonetheless, microsatellite-associated polymorphisms may facilitate the adaptability of $P$. malariae in primate hosts, including South American primates and chimpanzees [49].

AT-richness of the $P$. malariae and $P$. ovale curtisi genomes was in accordance with the high AT content (89\%) of CDS-associated microsatellite sequences. Additionally, hydrophilic amino acids such as lysine and asparagine were among the most commonly repeated amino acid motifs observed, which is consistent with the natural bias towards hydrophilic amino acids in proteins [26]. Lysine-rich short tandemly repeated sequences have been observed in different protozoal parasites, including P. falciparum and Leishmania major. These parasites are suggested to generate such amino acid sequences de novo to modulate host protein targeting efficiency $[11,36]$. Because microsatellite instability in CDS could increase the chance of forming mutant proteins, the study of GO terms for such CDS-associated proteins should not be ignored. Although GO analysis of microsatellite-related CDS has been fairly limited to UniProtKB-based interpretation of known protein sequences, an overview of annotation for cellular components, molecular functions, and biological processes may be useful for high-level interpretation of microsatelliteassociated proteins. In $P$. malariae and $P$. ovale curtisi, the majority of ontological terms for proteins associated with microsatellite-containing CDS were assigned to "cell parts," 
"binding," "metabolic process," and "response to stimuli" which are often linked to cellular integrity, adaptation, and survival of pathogens [3, 6, 15]. The relationship between microsatellite content and plasticity of these ontologies is an interesting area for further study.

An important aspect of the genome-wide microsatellite mapping in this study is to facilitate development of genotyping markers. Unlike SNP and DNA barcoding, microsatellite markers can be evaluated for the entire genome of an organism [7, 52]. Although SNPs in merozoite surface proteins ( $m s p) 1$ and msp 2 have been used to investigate polymorphisms in Plasmodium species, the pressure from the selective host immune system often reduces polymorphisms and subsequently lowers the application of such protein gene-based markers [9, 31]. In contrast, the majority of microsatellites are in noncoding regions that can achieve a high degree of polymorphism, making it a suitable marker for discriminating variants within a population and drug efficacy studies [27, 64]. Mass drug administration programs expose a parasite to antimalarials, which further suggests the urgency in investigating genetic diversity within $P$. malariae and $P$. ovale curtisi [63]. Although identification of genotyping markers for these parasites is beyond the scope of the current investigation, this study contributes the first comprehensive knowledge on genome-wide features and 1-10 bp unit motif microsatellite diversity for $P$. malariae and $P$. ovale curtisi. Utilization of these computational outcomes could assist in the identification of novel microsatellite markers for haplotype clustering, population differentiation, and linkage disequilibrium, as demonstrated by the success of such in silico-based studies in the past for $P$. falciparum, $P$. vivax, and Leishmania panamensis $[2,24,46]$.

In conclusion, this study presents the first comprehensive categorization of mono- to deca-nucleotide microsatellites in five human malaria-causing Plasmodium species. The results indicate high diversity in the CDS and genomic microsatellite distribution across all investigated species of Plasmodium. In $P$. malariae and $P$. ovale curtisi, the high density of microsatellite distribution observed warrants further in-depth investigation to identify potential genotyping markers for epidemiological studies.

\section{Supplementary materials}

Supplementary material is available at https://www.parasitejournal.org/10.1051/parasite/2020034/olm

Supplementary Table 1. Categorization of the most frequently repeated microsatellite motifs in genomes of Plasmodium species.

Supplementary Table 2. Diversity and motif length-wise distribution of chromosomal microsatellite in P. malariae UG01.

Supplementary Table 3. Diversity and motif length-wise distribution of chromosomal microsatellite in P. ovale curtisi.

Supplementary Figure 1. Chromosomal lengthwise distribution of microsatellites based on unit motif length in Plasmodium malariae UG01. The subplots (A-N) indicate lengthwise distribution of microsatellites in chromosomes 1-14 separated according to the unit motif length of microsatellites identified for each chromosome. Width of each violin plot indicates relative densities of microsatellites in the region. (O) Summary of microsatellite densities in each chromosome of $P$. malariae UG01.

Supplementary Figure 2. Chromosomal lengthwise distribution of microsatellites based on unit motif length in Plasmodium ovale curtisi $\mathrm{GH} 01$. The subplots $(\mathrm{A}-\mathrm{N})$ indicate lengthwise distribution of microsatellites in chromosomes 1-14 separated according to the unit motif length of microsatellites identified for each chromosome. Width of each violin plot indicates relative densities of microsatellites in the region. (O) Summary of microsatellite densities in each chromosome of $P$. ovale curtisi GH01.

Supplementary Figure 3. Representative chart for the density of microsatellite distribution in Plasmodium malariae UG01 (left) and P. ovale curtisi GH01 (right) chromosomes. Overall representation chart of (A) the microsatellite density distribution (B) gradient-wise distribution of the core regions with maximum microsatellite densities for chromosome 8 in P. malariae.

$\begin{array}{ll}\text { Abbreviations } \\ \text { AUC } & \text { area under curve } \\ \text { bp } & \text { Base pair } \\ \text { CDS } & \text { Protein-coding-regions } \\ \text { GO } & \text { Gene ontology } \\ \text { HE } & \text { Heterozygosity } \\ \text { Kbp } & \text { Kilo base pair } \\ \text { Mbp } & \text { Million base pair } \\ \text { ORFs } & \text { Open reading frame } \\ \text { SNP } & \text { Single nucleotide polymorphisms }\end{array}$

\section{Authors' contribution statement}

VBM and MI designed the study. VBM preformed the data analysis and wrote the first draft of the manuscript. SN assisted in part of data analysis. NJW and AMD assisted in logistic support and manuscript preparation. All authors read and approved the final manuscript.

\section{Funding}

The research was funded by postdoctoral research sponsorship of Mahidol University, Thailand, Thailand Science Research and Innovation (TSRI), grant no. RTA6280006 and the Wellcome Trust of Great Britain, UK.

\section{Availability of data and materials}

The datasets generated during the current study are available from the corresponding author on reasonable request.

\section{Ethics approval and consent to participate}

None required.

Acknowledgements. This study was supported by Mahidol University, the Thailand Research Fund, Thailand and the Wellcome Trust of Great Britain. 


\section{Conflict of interest}

The authors declare that they have no competing interests.

\section{References}

1. Anderson TJ, Su XZ, Bockarie M, Lagog M, Day KP. 1999. Twelve microsatellite markers for characterization of Plasmodium falciparum from finger-prick blood samples. Parasitology, 119, 113-125.

2. Anderson TJ, Haubold B, Williams JT, Estrada-Franco JG, Richardson L, Mollinedo R, Bockarie M, Mokili J, Mharakurwa S, French N, Whitworth J, Velez ID, Brockman AH, Nosten F, Ferreira MU, Day KP. 2000. Microsatellite markers reveal a spectrum of population structures in the malaria parasite Plasmodium falciparum. Molecular Biology and Evolution, 17, 1467-1482.

3. Arnaud MB, Costanzo MC, Shah P, Skrzypek MS, Sherlock G. 2009. Gene Ontology and the annotation of pathogen genomes: the case of Candida albicans. Trends in Microbiology, 17(7), 295-303.

4. Aurrecoechea C, Brestelli J, Brunk BP, Dommer J, Fischer S, Gajria B, Gao X, Gingle A, Grant G, Harb OS, Heiges M, Innamorato F, Iodice J, Kissinger JC, Kraemer E, Li W, Miller JA, Nayak V, Pennington C, Pinney DF, Roos DS, Ross C, Stoeckert CJ Jr, Treatman C, Wang H. 2009. PlasmoDB: a functional genomic database for malaria parasites. Nucleic Acids Research, 37(Database issue), D539-D543.

5. Bethke L, Thomas S, Walker K, Lakhia R, Rangarajan R, Wirth D. 2007. The role of DNA mismatch repair in generating genetic diversity and drug resistance in malaria parasites. Molecular and Biochemical Parasitology, 155(1), 18-25.

6. Brehelin L, Dufayard JF, Gascuel O. 2008. PlasmoDraft: a database of Plasmodium falciparum gene function predictions based on postgenomic data. BMC Bioinformatics, 9, 440.

7. Castagnone-Sereno P, Danchin EG, Deleury E, Guillemaud T, Malausa T, Abad P. 2010. Genome-wide survey and analysis of microsatellites in nematodes, with a focus on the plant-parasitic species Meloidogyne incognita. BMC Genomics, 11, 598.

8. Chen M, Zeng G, Tan Z, Jiang M, Zhang J, Zhang C, Lu L, Lin Y, Peng J. 2011. Compound microsatellites in complete Escherichia coli genomes. FEBS Letters, 585, 1072-1076.

9. Cochrane AH, Collins WE, Nussenzweig RS. 1984. Monoclonal antibody identifies circumsporozoite protein of Plasmodium malariae and detects a common epitope on Plasmodium brasilianum sporozoites. Infection and Immunity, 45(3), 592-595.

10. Dallas JF. 1992. Estimation of microsatellite mutation rates in recombinant inbred strains of mouse. Mammalian Genome, 3, 452-456.

11. Davies HM, Thalassinos K, Osborne AR. 2016. Expansion of lysine-rich repeats in Plasmodium proteins generates novel localization sequences that target the periphery of the host erythrocyte. Journal of Biological Chemistry, 291, 26,188$26,207$.

12. Douglas NM, Lampah DA, Kenangalem E, Simpson JA, Poespoprodjo JR, Sugiarto P, Anstey NM, Price RN. 2013. Major burden of severe anemia from non-falciparum malaria species in Southern Papua: a hospital-based surveillance study. PLoS Medicine, 10, e1001575.

13. Ellegren H. 2004. Microsatellites: simple sequences with complex evolution. Nature Reviews Genetics, 5, 435-445.

14. Fan H, Chu JY. 2007. A brief review of short tandem repeat mutation. Genomics, Proteomics \& Bioinformatics, 5, 7-14.
15. Felten A, Vila Nova M, Durimel K, Guillier L, Mistou MY, Radomski N. 2017. First gene-ontology enrichment analysis based on bacterial coregenome variants: insights into adaptations of Salmonella serovars to mammalian- and avian-hosts. BMC Microbiology, 17(1), 222.

16. Figan CE, Sa JM, Mu J, Melendez-Muniz VA, Liu CH, Wellems TE. 2018. A set of microsatellite markers to differentiate Plasmodium falciparum progeny of four genetic crosses. Malaria Journal, 17(1), 60.

17. Gilles HM, Hendrickse RG. 1963. Nephrosis in Nigerian children. Role of Plasmodium malariae, and effect of antimalarial treatment. British Medical Journal, 2, 27-31.

18. Gillings MR, Westoby M. 2014. DNA technology and evolution of the Central Dogma. Trends in Ecology \& Evolution, 29, 1-2.

19. Gomez JC, McNamara DT, Bockarie MJ, Baird JK, Carlton JM, Zimmerman PA. 2003. Identification of a polymorphic Plasmodium vivax microsatellite marker. American Journal of Tropical Medicine and Hygiene, 69(4), 377-379.

20. Greenhouse B, Myrick A, Dokomajilar C, Woo JM, Carlson EJ, Rosenthal PJ, Dorsey G. 2006. Validation of microsatellite markers for use in genotyping polyclonal Plasmodium falciparum infections. American Journal of Tropical Medicine and Hygiene, 75(5), 836-842.

21. Groger M, Veletzky L, Lalremruata A, Cattaneo C, Mischlinger J, Manego Zoleko R, Kim J, Klicpera A, Meyer EL, Blessborn D, Winterberg M, Adegnika AA, Agnandji ST, Kremsner PG, Mordmuller B, Mombo-Ngoma G, Fuehrer HP, Ramharter M. 2019. Prospective clinical and molecular evaluation of potential Plasmodium ovale curtisi and wallikeri relapses in a high-transmission setting. Clinical Infectious Diseases, 69(12), 2119-2126.

22. Guichoux E, Lagache L, Wagner S, Chaumeil P, Leger P, Lepais O, Lepoittevin C, Malausa T, Revardel E, Salin F, Petit RJ. 2011. Current trends in microsatellite genotyping. Molecular Ecology Resources, 11, 591-611.

23. Hamilton WL, Claessens A, Otto TD, Kekre M, Fairhurst RM, Rayner JC, Kwiatkowski D. 2017. Extreme mutation bias and high AT content in Plasmodium falciparum. Nucleic Acids Research, 45, 1889-1901.

24. Imwong M, Nair S, Pukrittayakamee S, Sudimack D, Williams JT, Mayxay M, Newton PN, Kim JR, Nandy A, Osorio L, Carlton JM, White NJ, Day NP, Anderson TJ. 2007. Contrasting genetic structure in Plasmodium vivax populations from Asia and South America. International Journal for Parasitology, 37, 1013-1022.

25. Jarne P, Lagoda PJ. 1996. Microsatellites, from molecules to populations and back. Trends in Ecology \& Evolution, 11, 424-429.

26. Katti MV, Sami-Subbu R, Ranjekar PK, Gupta VS. 2000. Amino acid repeat patterns in protein sequences: their diversity and structural-functional implications. Protein Science, 9, 1203-1209.

27. Koepfli C, Mueller I, Marfurt J, Goroti M, Sie A, Oa O, Genton B, Beck HP, Felger I. 2009. Evaluation of Plasmodium vivax genotyping markers for molecular monitoring in clinical trials. Journal of Infectious Diseases, 199(7), 1074-1080.

28. Lai Y, Sun F. 2003. The relationship between microsatellite slippage mutation rate and the number of repeat units. Molecular Biology and Evolution, 20, 2123-2131.

29. Langford S, Douglas NM, Lampah DA, Simpson JA, Kenangalem E, Sugiarto P, Anstey NM, Poespoprodjo JR, Price RN. 2015. Plasmodium malariae infection associated with a high burden of anemia: a hospital-based surveillance study. PLoS Neglected Tropical Diseases, 9, e0004195.

30. Levinson G, Gutman GA. 1987. High frequencies of short frameshifts in poly-CA/TG tandem repeats borne by 
bacteriophage M13 in Escherichia coli K-12. Nucleic Acids Research, 15, 5323-5338.

31. Liu Y, Zhou RM, Zhang YL, Wang DQ, Li SH, Yang CY, Qian D, Zhao YL, Zhang HW, Xu BL. 2018. Analysis of polymorphisms in the circumsporozoite protein gene of Plasmodium vivax isolates from Henan Province, China. Malaria Journal, 17(1), 103.

32. Lo E, Nguyen K, Nguyen J, Hemming-Schroeder E, Xu J, Etemesi H, Githeko A, Yan G. 2017. Plasmodium malariae prevalence and csp gene diversity, Kenya, 2014 and 2015. Emerging Infectious Diseases, 23(4), 601-610.

33. Lover AA, Baird JK, Gosling R, Price RN. 2018. Malaria elimination: time to target all species. American Journal of Tropical Medicine and Hygiene, 99(1), 17-23.

34. Mathema VB, Dondorp AM, Imwong M. 2019. OSTRFPD: Multifunctional tool for genome-wide short tandem repeat analysis for DNA, transcripts, and amino acid sequences with integrated primer designer. Evolutionary Bioinformatics Online, $15,1176934319843130$.

35. Mayer C. 2010. Phobos - a tandem repeat search tool for complete genomes. http://www.ruhr-uni-bochum.de/spezzoo/cm. Accessed on 25 April 2018.

36. Mendes TA, Lobo FP, Rodrigues TS, Rodrigues-Luiz GF, daRocha WD, Fujiwara RT, Teixeira SM, Bartholomeu DC. 2013. Repeat-enriched proteins are related to host cell invasion and immune evasion in parasitic protozoa. Molecular Biology and Evolution, 30, 951-963.

37. Menegon M, Bardaji A, Martinez-Espinosa F, BottoMenezes C, Ome-Kaius M, Mueller I, Betuela I, ArevaloHerrera M, Kochar S, Kochar SK, Jaju P, Hans D, Chitnis C, Padilla N, Castellanos ME, Ortiz L, Sanz S, Piqueras M, Desai M, Mayor A, Del Portillo H, Menendez C, Severini C. 2016. Microsatellite genotyping of Plasmodium vivax isolates from pregnant women in four malaria endemic countries. PloS One, 11(3), e0152447.

38. Metzgar D, Bytof J, Wills C. 2000. Selection against frameshift mutations limits microsatellite expansion in coding DNA. Genome Research, 10, 72-80.

39. Milner DA Jr. 2018. Malaria pathogenesis. Cold Spring Harbor Perspectives in Medicine, 8(1), a025569.

40. Mueller I, Zimmerman PA, Reeder JC. 2007. Plasmodium malariae and Plasmodium ovale - the "bashful" malaria parasites. Trends in Parasitology, 23(6), 278-283.

41. Nino CH, Cubides JR, Camargo-Ayala PA, Rodriguez-Celis CA, Quinones T, Cortes-Castillo MT, Sanchez-Suarez L, Sanchez R, Patarroyo ME, Patarroyo MA. 2016. Plasmodium malariae in the Colombian Amazon region: you don't diagnose what you don't suspect. Malaria Journal, 15, 576.

42. Nojadeh JN, Behrouz Sharif S, Sakhinia E. 2018. Microsatellite instability in colorectal cancer. EXCLI Journal, 17, 159-168.

43. Oguike MC, Betson M, Burke M, Nolder D, Stothard JR, Kleinschmidt I, Proietti C, Bousema T, Ndounga M, Tanabe K, Ntege E, Culleton R, Sutherland CJ. 2011. Plasmodium ovale curtisi and Plasmodium ovale wallikeri circulate simultaneously in African communities. International Journal for Parasitology, 41(6), 677-683.

44. Olson M, Hood L, Cantor C, Botstein D. 1989. A common language for physical mapping of the human genome. Science, 245(4925), 1434-1435.

45. Orjuela-Sanchez P, Sa JM, Brandi MC, Rodrigues PT, Bastos MS, Amaratunga C, Duong S, Fairhurst RM, Ferreira MU. 2013. Higher microsatellite diversity in Plasmodium vivax than in sympatric Plasmodium falciparum populations in Pursat, Western Cambodia. Experimental Parasitology, 134(3), 318-326.
46. Oyebola MK, Idowu ET, Nyang H, Olukosi YA, Otubanjo OA, Nwakanma DC, Awolola ST, Amambua-Ngwa A. 2014. Microsatellite markers reveal low levels of population substructuring of Plasmodium falciparum in southwestern Nigeria. Malaria Journal, 13, 493.

47. Roman DNR, Rosalie NNA, Kumar A, Luther KMM, Singh V, Albert MS. 2018. Asymptomatic Plasmodium malariae infections in children from suburban areas of Yaounde, Cameroon. Parasitology International, 67(1), 29-33.

48. Roucher C, Rogier C, Sokhna C, Tall A, Trape JF. 2014. A 20-year longitudinal study of Plasmodium ovale and Plasmodium malariae prevalence and morbidity in a West African population. PloS One, 9(2), e87169.

49. Rutledge GG, Bohme U, Sanders M, Reid AJ, Cotton JA, Maiga-Ascofare O, Djimde AA, Apinjoh TO, Amenga-Etego L, Manske M, Barnwell JW, Renaud F, Ollomo B, Prugnolle F, Anstey NM, Auburn S, Price RN, McCarthy JS, Kwiatkowski DP, Newbold CI, Berriman M, Otto TD. 2017. Plasmodium malariae and $P$. ovale genomes provide insights into malaria parasite evolution. Nature, 542, 101-104.

50. Rutledge GG, Marr I, Huang GKL, Auburn S, Marfurt J, Sanders M, White NJ, Berriman M, Newbold CI, Anstey NM, Otto TD, Price RN. 2017. Genomic characterization of recrudescent Plasmodium malariae after treatment with artemether/lumefantrine. Emerging Infectious Diseases, 23, $1300-1307$.

51. Saralamba N, Mayxay M, Newton PN, Smithuis F, Nosten F, Archasuksan L, Pukrittayakamee S, White NJ, Day NPJ, Dondorp AM, Imwong M. 2018. Genetic polymorphisms in the circumsporozoite protein of Plasmodium malariae show a geographical bias. Malaria Journal, 17(1), 269.

52. Schindel DE, Miller SE. 2005. DNA barcoding a useful tool for taxonomists. Nature, 435, 17.

53. Schindler T, Robaina T, Sax J, Bieri JR, Mpina M, Gondwe L, Acuche L, Garcia G, Cortes C, Maas C, Daubenberger C. 2019. Molecular monitoring of the diversity of human pathogenic malaria species in blood donations on Bioko Island, Equatorial Guinea. Malaria Journal, 18(1), 9.

54. Selkoe KA, Toonen RJ. 2006. Microsatellites for ecologists: a practical guide to using and evaluating microsatellite markers. Ecology Letters, 9, 615-629.

55. Sharma PC, Grover A, Kahl G. 2007. Mining microsatellites in eukaryotic genomes. Trends in Biotechnology, 25, 490-498.

56. Simbaqueba J, Sanchez P, Sanchez E, Nunez Zarantes VM, Chacon MI, Barrero LS, Marino-Ramirez L. 2011. Development and characterization of microsatellite markers for the Cape gooseberry Physalis peruviana. PloS One, 6, e26719.

57. Soontarawirat I, Andolina C, Paul R, Day NPJ, Nosten F, Woodrow CJ, Imwong M. 2017. Plasmodium vivax genetic diversity and heterozygosity in blood samples and resulting oocysts at the Thai-Myanmar border. Malaria Journal, 16(1), 355 .

58. Szalkai B, Grolmusz V. 2018. SECLAF: a webserver and deep neural network design tool for hierarchical biological sequence classification. Bioinformatics, 34, 2487-2489.

59. Tan JC, Tan A, Checkley L, Honsa CM, Ferdig MT. 2010. Variable numbers of tandem repeats in Plasmodium falciparum genes. Journal of Molecular Evolution, 71, 268-278.

60. Toth G, Gaspari Z, Jurka J. 2000. Microsatellites in different eukaryotic genomes: survey and analysis. Genome Research, 10, 967-981.

61. Trevino SG, Nkhoma SC, Nair S, Daniel BJ, Moncada K, Khoswe S, Banda RL, Nosten F, Cheeseman IH. 2017. Highresolution single-cell sequencing of malaria parasites. Genome Biology and Evolution, 9, 3373-3383. 
62. Trimarsanto H, Benavente ED, Noviyanti R, Utami RA, Trianty L, Pava Z, Getachew S, Kim JY, Goo YK, Wangchuck S, Liu Y, Gao Q, Dowd S, Cheng Q, Clark TG, Price RN, Auburn S. 2017. VivaxGEN: an open access platform for comparative analysis of short tandem repeat genotyping data in Plasmodium vivax populations. PLoS Neglected Tropical Diseases, 11, e0005465.

63. Tripura R, Peto TJ, Chea N, Chan D, Mukaka M, Sirithiranont P, Dhorda M, Promnarate C, Imwong M, von Seidlein L, Duanguppama J, Patumrat K, Huy R, Grobusch MP, Day NPJ, White NJ, Dondorp AM. 2018. A controlled trial of mass drug administration to interrupt transmission of multidrug-resistant falciparum malaria in Cambodian villages. Clinical Infectious Diseases, 67(6), 817-826.

64. Vieira ML, Santini L, Diniz AL, Munhoz Cde F. 2016. Microsatellite markers: what they mean and why they are so useful. Genetics and Molecular Biology, 39, 312-328.

65. Weber JL, Wong C. 1993. Mutation of human short tandem repeats. Human Molecular Genetics, 2, 1123-1128.
66. WHO. 2016. Eliminating malaria in the Greater Mekong Subregion: united to end a deadly disease. p. 24.

67. Yamamoto H, Imai K. 2015. Microsatellite instability: an update. Archives of Toxicology, 89(6), 899-921.

68. Yman V, Wandell G, Mutemi DD, Miglar A, Asghar M, Hammar U, Karlsson M, Lind I, Nordfjell C, Rooth I, Ngasala B, Homann MV, Farnert A. 2019. Persistent transmission of Plasmodium malariae and Plasmodium ovale species in an area of declining Plasmodium falciparum transmission in eastern Tanzania. PLoS Neglected Tropical Diseases, 13(5), e0007414.

69. Zhou M, Liu Q, Wongsrichanalai C, Suwonkerd W, Panart K, Prajakwong S, Pensiri A, Kimura M, Matsuoka H, Ferreira MU, Isomura S, Kawamoto F. 1998. High prevalence of Plasmodium malariae and Plasmodium ovale in malaria patients along the Thai-Myanmar border, as revealed by acridine orange staining and PCR-based diagnoses. Tropical Medicine \& International Health, 3(4), 304-312.

Cite this article as: Mathema VB, Nakeesathit S, White NJ, Dondorp AM \& Imwong M. 2020. Genome-wide microsatellite characteristics of five human Plasmodium species, focusing on Plasmodium malariae and P. ovale curtisi. Parasite 27, 34.

- PARASTTE

An international open-access, peer-reviewed, online journal publishing high quality papers on all aspects of human and animal parasitology

Reviews, articles and short notes may be submitted. Fields include, but are not limited to: general, medical and veterinary parasitology; morphology, including ultrastructure; parasite systematics, including entomology, acarology, helminthology and protistology, and molecular analyses; molecular biology and biochemistry; immunology of parasitic diseases; host-parasite relationships; ecology and life history of parasites; epidemiology; therapeutics; new diagnostic tools.

All papers in Parasite are published in English. Manuscripts should have a broad interest and must not have been published or submitted elsewhere. No limit is imposed on the length of manuscripts.

Parasite (open-access) continues Parasite (print and online editions, 1994-2012) and Annales de Parasitologie Humaine et Comparée (1923-1993) and is the official journal of the Société Française de Parasitologie. 